\title{
Conceptual design of biomass-fired cogeneration plant through a knowledge-based system
}

\author{
José Alexandre Matelli
}

Received: 28 April 2014 / Accepted: 14 February 2015 / Published online: 18 March 2015

(C) The Brazilian Society of Mechanical Sciences and Engineering 2015

\begin{abstract}
Industries such as sugar/ethanol and paper/ pulp generate large amount of biomass as by-products that must be properly handled to avoid environmental damage. A synergetic alternative to address this issue is to use the residual biomass as fuel in a cogeneration plant. In this work, it is presented the development of a knowledgebased system for conceptual design of biomass cogeneration plants. Elicitation from experts and technical literature provides knowledge for the base. A knowledge representation scheme composed of rules, object-oriented and semantic nets because it is flexible enough to cope with future knowledge base expansion. For rapid prototyping, a shell is used to implement the knowledge base. As a result, the system is able to quickly provide high quality conceptual solutions of biomass-fired cogeneration plants to support the designer in his/her decision making.
\end{abstract}

Keywords Cogeneration - Knowledge-based systems · Biomass · Conceptual design

\section{Introduction}

Some industries, such as sugar/ethanol and paper/pulp, generate large amount of biomass as by-products that must be properly handled to avoid environmental damage. A

Technical Editor: Fernando Antonio Forcellini.

To be submitted to the Journal of the Brazilian Society of Mechanical Sciences and Engineering, Guaratinguetá, falls 2014.

J. A. Matelli $(\bowtie)$

Department of Energy, UNESP, University Estadual Paulista, Guaratinguetá, SP 12516-410, Brazil

e-mail: matelli@feg.unesp.br synergetic alternative to address this issue is to use residual biomass as fuel in a cogeneration plant. Thus, environmental damage is mitigated while power and useful heat (typically steam) are simultaneously generated.

A cogeneration plant is a thermal system, i.e., a collection of components with interrelated performance. Gas turbines fueled by gas generated through biomass gasification or fuel cells fed by hydrogen obtained also from biomass gasification are state-of-the-art technologies for cogeneration, but they are still not mature enough to be competitive $[1,2]$. Thus, the main technology commercially available is the classical Rankine cycle. Biomass is burned in a steam generator that provides high pressure, superheated steam to a steam turbine. A generator coupled to the turbine shaft generates power, and extractions in turbine casing provide steam at different pressure level for the respective processes. In addition, heat exchangers, cooling towers, condensate tanks, deaerators, pumps, fans and other components are typically found in cogeneration plants. Following its fundamental concepts, different configurations based on Rankine cycle have been usually considered to organize the structural elements of design.

The goal of conceptual design of any mechanical system is to generate several alternatives able to meet design requirements [3]. For cogeneration plants, main design requirements are power and heat demands. It is essential to generate alternatives with sufficient quality to merit further analysis and optimization [4]. In other words, it is not worth to optimize a design that is bad from the scratch. Furthermore, the need for increasing efficiency, cost reduction and environmental impacts minimization contributes to increase the complexity of energy systems. Such complexity demands increasing knowledge, creativity and experience from engineers involved with conceptual design, which explain the heuristic nature of the 
problem. This kind of problem can be well approached through an artificial intelligence technique known as knowledge-based system. ${ }^{1}$ Knowledge-based systems (KBS) have been successfully applied to different engineering designs [5-7] and energy system designs [8-11]. This technique is also suited for analytic tasks, such as diagnostics [12].

The objective of this work is to present a KBS rapid prototype for conceptual design of biomass-fired cogeneration plants. The use of the KBS is intended to assist the engineer in creating different concepts, because the design of such plants is inherently complex due to possible existence of several alternatives that fulfill a certain set of power and heat demands.

\section{Methodology}

Conceptual design of energy systems is a feasible domain for KBS because the required knowledge (the laws of Thermodynamics) is well established. The present work focuses on the first two of four phases of design activity as proposed by Pahl et al. [3]:

(i) Task clarification: information related to the plant requirements is collected. The result of this phase is the information specification;

(ii) Conceptual design: one or more principle of solutions able to meet the information specified in previous phase is generated. This is the phase that mostly demands creativity, experience and knowledge. The result of this phase is the specification of one or more principle of solution;

(iii) Preliminary design: a technically feasible, executable solution is generated from a principle of solution obtained in conceptual phase. This solution is refined until it is possible to evaluate it economically. The decisions made here must be mathematically and physically justified. The result of this phase is the specification of a configuration.

(iv) Detailed design: all materials and components are specified, costs are estimated and documentation (blueprints, diagrams) is provided to execute the project. The result of this phase is the specification of the execution.

Basically, KBS development involves: a knowledge elicitation from acknowledged experts; $b$ knowledge representation; and c computational implementation.

\subsection{Knowledge elicitation}

Knowledge elicitation is made mainly through technical literature $[4,13-16]$ and unstructured interviews with experts in the field. In general, such knowledge presents a heuristic nature. According to Giarratano and Riley [17], "heuristics are rules of thumb or empirical knowledge gained from experience that may aid in the solution but are not guaranteed to work. However, in many fields, such as medicine and engineering, heuristics play an essential role in some types of problem solving". The knowledge chunks elicited from the experts are summarized as follows:

a. The main information needed for designing biomass cogeneration plants are thermal and electrical demands, operating mode (power match or thermal match), type and availability of fuel, and water availability for cooling;

b. Operating mode depends on the possibility of commercialization of an eventual exceeding power generated by the plant. If commercialization is possible, plant should operate in thermal-match mode. There are two cases where commercialization is not possible: (i) local utility has no interest in this type of business; (ii) plant is stand-alone. In both cases, plant should operate in power-match mode;

c. There are three possible ways to generate power from biomass: (i) the most usual is burning biomass in boilers to generate high pressure steam for turbine driving; (ii) the syngas obtained from biomass gasification is burned in a gas turbine generator set; (iii) the syngas from gasification is purified to obtain hydrogen for a fuel cell. Alternatives (ii) and (iii) are still not mature enough to compete with alternative (i), which is considered in the KBS;

d. In general, saturated steam is the thermal demand of industries that have biomass as by-products. There may be several processes, each one requiring a specific pressure. Rarely the pressure required in thermal processes exceeds $2 \mathrm{MPa}$. Thus, this value is an upper limit set in the KBS;

e. Steam flow is highly variable depending on the industrial process. An upper limit of $4 \mathrm{~kg} / \mathrm{s}$ per process is stipulated. The number of process is limited to 5 (see item g);

f. In Brazil, the industries that generate biomass as byproduct and demand steam are rice grain processing, sugar/alcohol mills and pulp/paper mills;

g. In both extraction-condensing and back-pressure turbines, steam at positive pressure is directly extracted at intermediate points in the turbine casing. Steam pressure depends on the extraction point location: the closer the location to the steam inlet, the higher is

$\overline{1}$ Also known as expert systems. 
the pressure. In extraction-condensing turbines, there is an exclusive outlet to steam at negative pressure for the condenser, on which no $<20 \%$ of inlet steam flow must pass. In back-pressure turbines, there is no such outlet and the steam at the lowest pressure is exhausted for the process that requires that pressure. Turbine casing constructive features limit the number of extractions to 5 .

h. Turbine choice depends on the plant operation mode. In power-match mode, extraction-condensing turbine is recommended because it allows a better power generation control. Back-pressure turbine (BPT) is recommended for thermal-match mode, which makes the power generation dependent on the thermal demand. Extraction-condensing turbines can also be used for thermal-match mode, but in this case a critical cost benefit analysis must be performed. It is stipulated that each plant has only one turbine and the upper limit for power demand is $30 \mathrm{MW}$;

i. The efficiency of turbines and pumps is typically between 0.70 and 0.88 [16]. Flame-tube boilers present efficiency between 0.82 and 0.86 , and water-tube boilers between 0.85 and 0.90 [13].

j. Flame-tube boilers generate only saturated steam, which is not suitable for mechanical driving. Thus, its use in cogeneration plants requires the adaptation of a superheater. Although very cost competitive, the use of flame-tube boilers in cogeneration is rare due to the constraints on pressure and flow (2.5 MPa and $5.6 \mathrm{~kg} / \mathrm{s}$, respectively [13]). Water-tube boilers can generate both saturated and superheated steam and present flexible operation, with higher limits of pressure and flow (10 MPa and $41.7 \mathrm{~kg} / \mathrm{s}$, respectively [13]). Despite their high initial cost, water-tube boilers are widely used in cogeneration from biomass;

k. Water availability for cooling determines how heat is rejected in the condenser. For high availability (e.g., a river), the condenser can be a shell-and-tube heat exchanger, with steam flowing in the shell and fresh water in the tubes. The alternatives are: (i) condenser is a shell-and-tube heat exchanger, but water circulates between the tubes and a wet cooling tower (WCT); (ii) condenser is a shell-and-tube heat exchanger, but water circulates between the tubes and a dry cooling tower; (iii) condenser is a cross-flow heat exchanger with finned tubes, with the steam circulating inside the tubes and air blown by a fan passes through the outside. The last alternative is not common.

\subsection{Knowledge representation}

In this work, knowledge is represented through a combination of rules, object-oriented modeling and semantic
Table 1 Conceptual design steps

\begin{tabular}{lll}
\hline Step & Description & Number of rules \\
\hline 1 & Circuit selection & 15 \\
2 & Circuit combination & 10 \\
3 & Determination of thermodynamic states & 23 \\
4 & Component sizing & 11 \\
5 & Explanation (design rationale) & 17 \\
6 & Output files generation (solution) & 2 \\
\hline
\end{tabular}

network. This knowledge representation scheme allows an adequate code management and system expansion, and was successfully applied in previous expert systems for engineering design $[5,11]$. Additionally, the plant-object is modeled as a combination of circuit-objects, each one with a specific function (e.g., power generation). A circuit is a combination of components interconnected to perform that function (e.g., a power generation circuit may be composed of an extraction-condensing turbine, deaerator, water-tube boiler, pumps, condenser etc.). If power and steam are required, the cogeneration plant must be a proper combination of a power generation circuit with a steam generation circuit. Note that there may be different circuits performing the same function, so that different circuit combinations may be generated to meet the same energy demands.

\subsubsection{Rules}

The core of the system knowledge base is a predetermined set of rules obtained through elicitation from technical literature and acknowledged experts. Rules are a quite natural way to represent knowledge, especially in domains on which the knowledge accumulation over the years results in internal empirical associations, i.e., the heuristics. Each step of the conceptual phase is related to a group of rules, as shown in Table 1. Despite the unstructured nature of KBS, rule grouping brings some structure to the system and allows a better control of information flow. Current KBS knowledge base has 78 rules, two of them basically related to output files generation. Since it is not possible to present all the rules in this paper, just one rule per step is presented. The rules are presented in a pictorial fashion to abstract any detail related to programming syntax, as shown in Figs. 1, 2, 3, 4, 5 .

Rule depicted in Fig. 1 controls the KBS information flow, which is related to the steps shown in Table 1. The rule identifies the end of each step, invalidates the control fact of the concluded step and creates the control fact of the new step.

There are four premises in the rule shown in Fig. 2. The first one is the control fact assuring that KBS is performing inferences related to circuit selection step. The second 
Fig. 1 Control rule

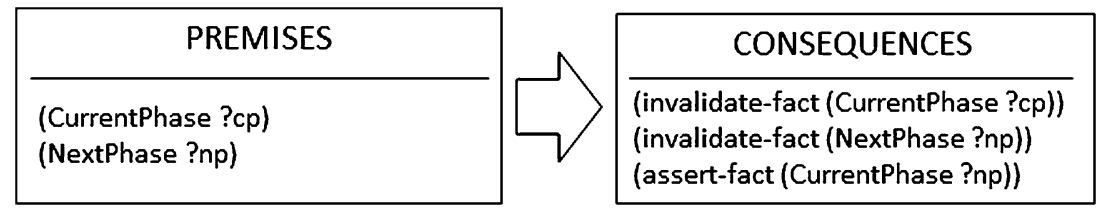

Fig. 2 Rule to select a specific power generation circuit

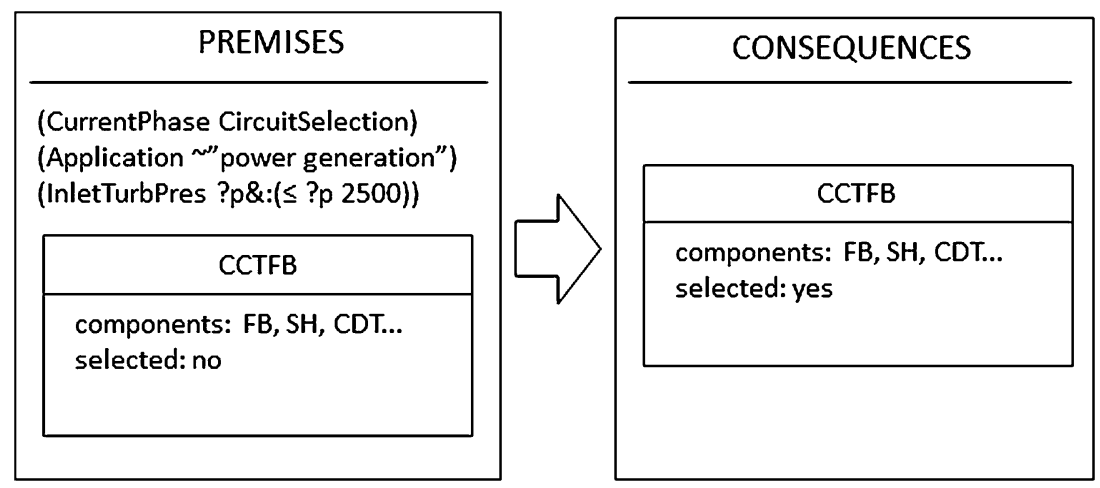

Fig. 3 Rule for circuit combination

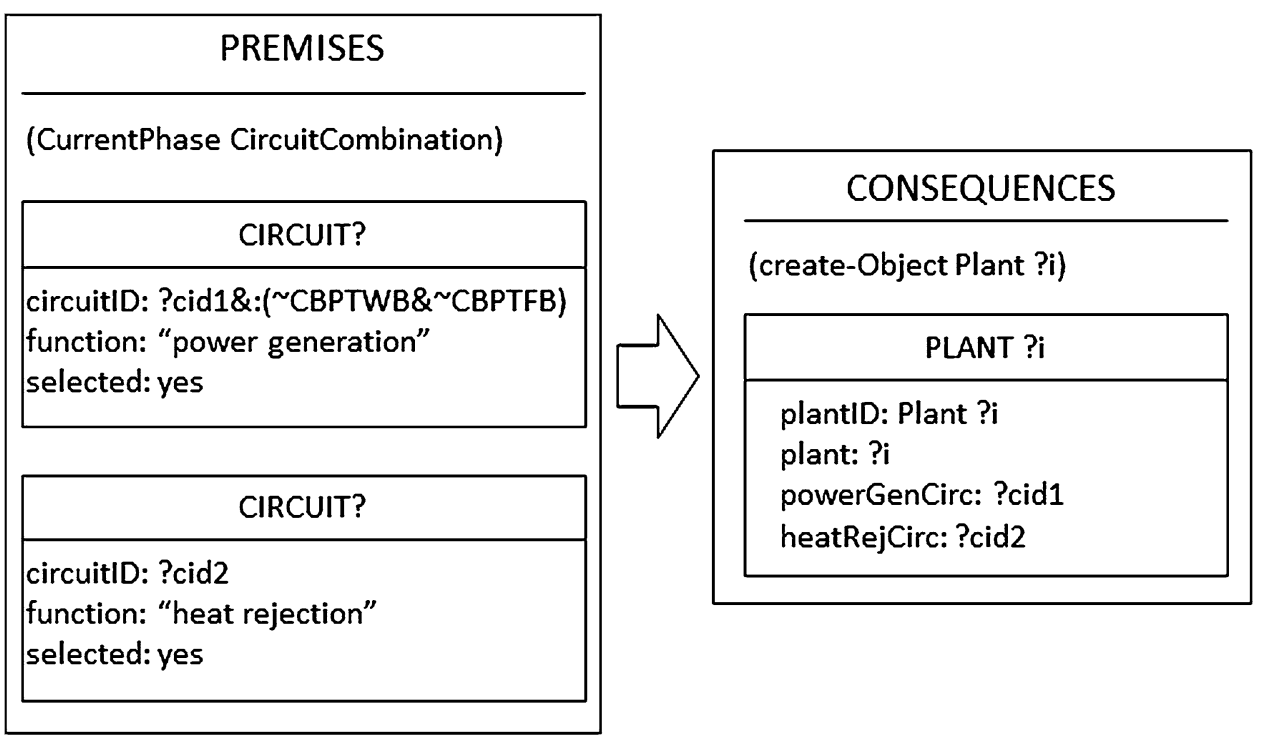

premise relates to the plant application, which cannot ${ }^{2}$ be pure power generation in this case. The third premise refers to the upper limit of pressure in flame-tube boilers (see Sect. 2.1, item j), i.e., the pressure represented through the variable ?p can assume any value $<2.5 \mathrm{MPa}$. Last premise is an object named CCTFB (an acronym to Circuit Condensing Turbine Flame-tube Boiler, referring to the main components of the circuit). This object presents two attributes: the list of components and whether it is selected. If all premises are satisfied, the rule changes the selection-attribute value to yes. Object-oriented modeling is detailed ahead in Sect. 2.2.2.

\footnotetext{
2 The $\sim$ symbol represents negation.
}

The rule depicted in Fig. 3 combines power generation circuits with heat rejection circuits. Besides the control fact, the premises are the objects to be combined. There is a compatibility criterion explicit in the circuitID-attribute of the object which the function-attribute is "power generation". The criterion is: any power generation circuit not based on BPT can be combined with any heat rejection circuit. The rule action is to create a plant-object that represents the combination of these circuits. Note that the rule creates as many plants as there are circuit combinations. Thus, there may be more than one solution capable to meet the design requirements, a desirable situation in conceptual design phase according with Pahl et al. [3]. Similar rules represent knowledge 
Fig. 4 Rule for thermodynamic state determination

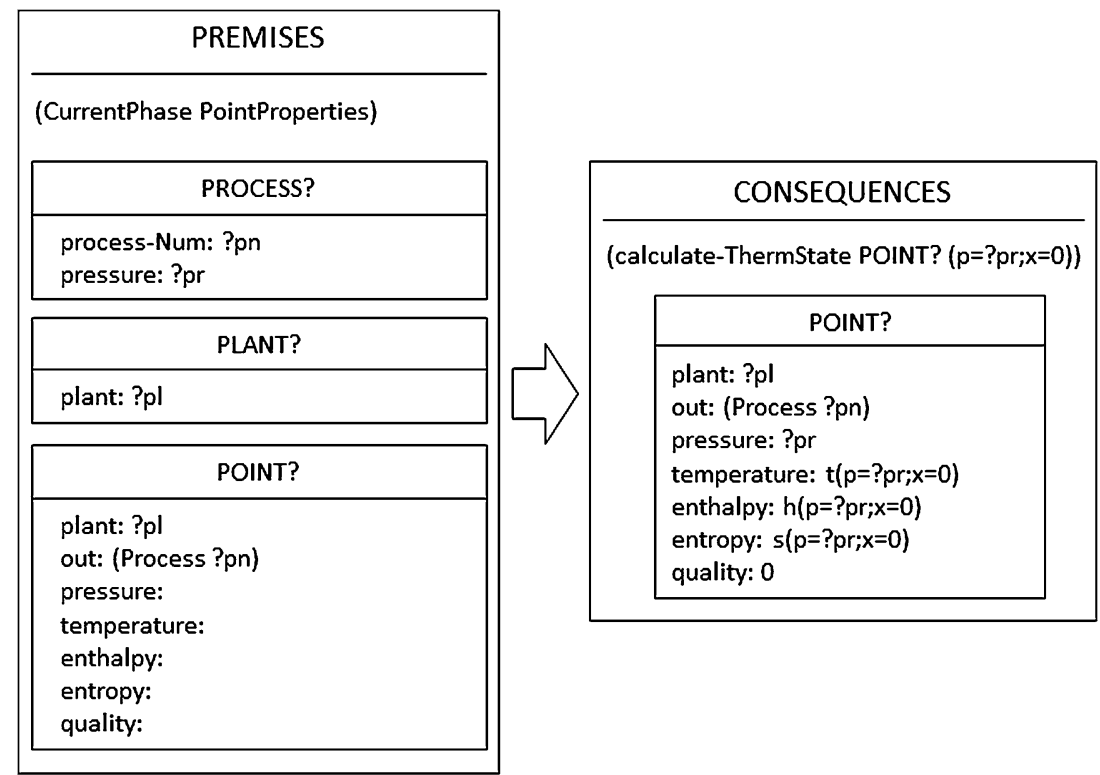

Fig. 5 Rule for boiler sizing

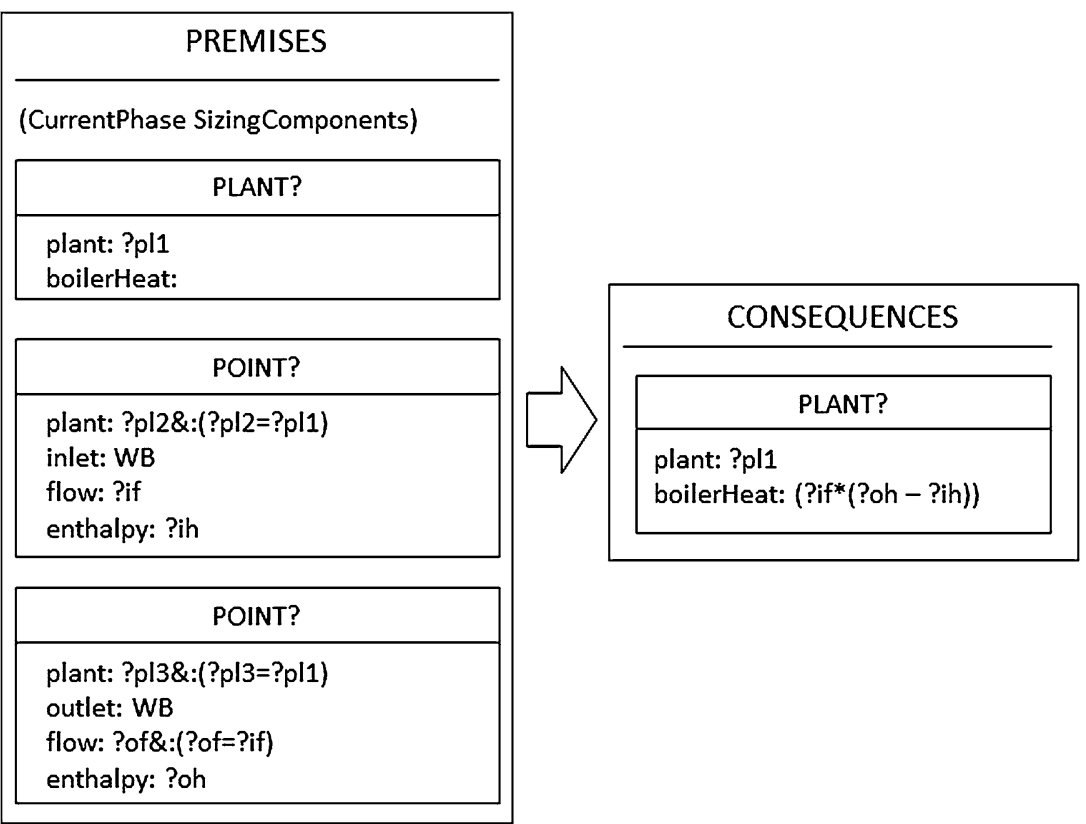

for combining power generation circuits with steam generation circuits.

A rule to determine the thermodynamic state in a given point is depicted in Fig. 4. In this particular case, the points correspond to the processes outlet and are assumed as saturated liquid. A plant-object is a rule premise because, depending on the plant configuration, point labeling can differ from one plant to another. The rule action is to calculate the thermodynamic state of that object representing the outlet point of the process ?op. The procedure requires two thermodynamic properties that in this particular case are process pressure (?pr) and quality equal to zero. Details of the implementation of this procedure are given ahead in Sect. 2.2.3. Similarly, other rules represent the knowledge to determine the thermodynamic state of other points.

A rule referring to the thermal sizing of component is shown in Fig. 5. In this particular case, the rule refers to the calculation of the heat transferred to the boiler. As expected, there are similar rules for thermal sizing of other components. Finally, in Fig. 6 is depicted a rule that explains why power generation circuit $\mathrm{CCTWB}^{3}$ is selected. In this case, ?exp is a string variable with the following value:

\footnotetext{
${ }^{3}$ Circuit Condensing Turbine Water-tube Boiler.
} 
Fig. 6 Rule to explain the selection of a specific power circuit
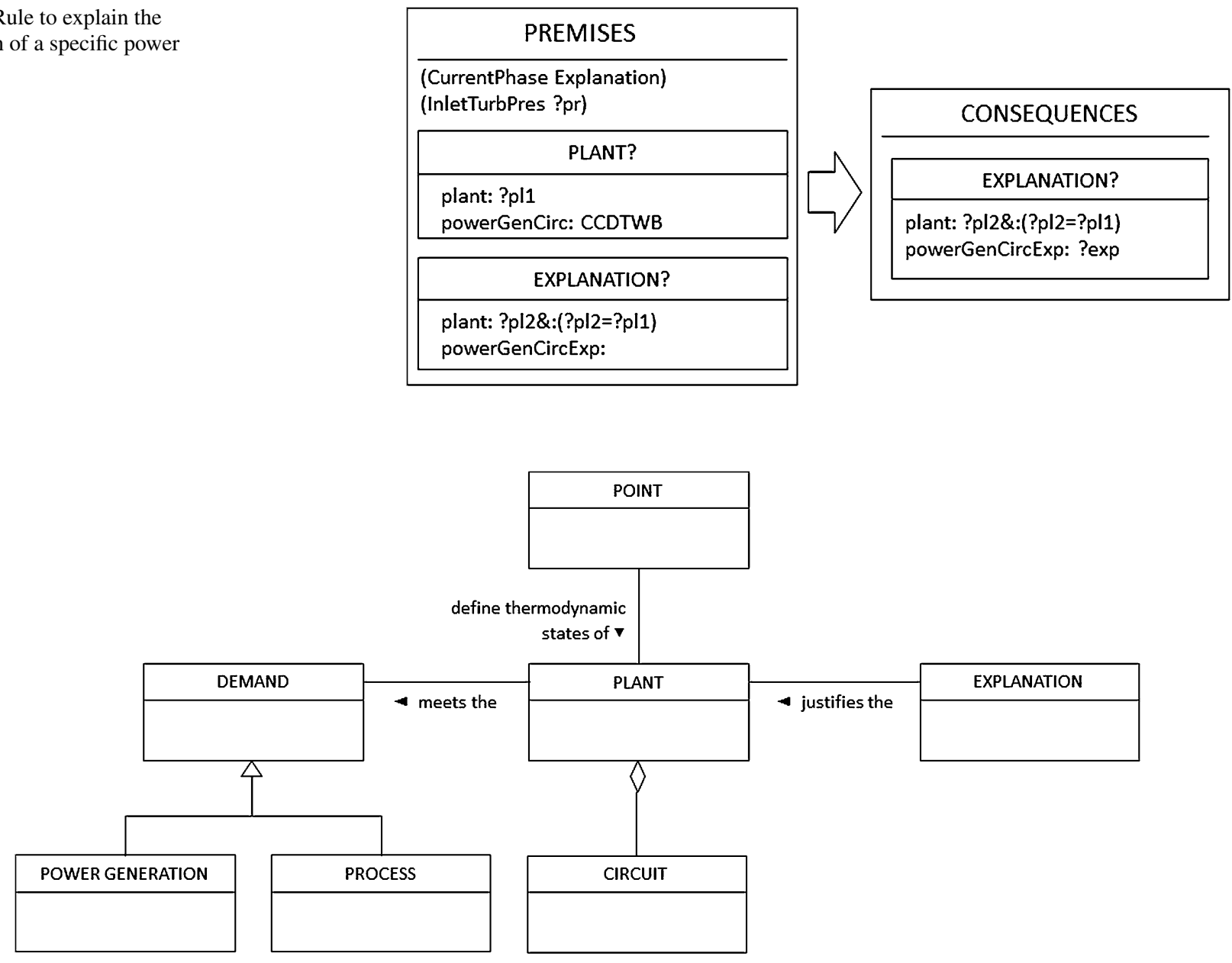

Fig. 7 Ontology defined for the considered domain

\section{(?exp}

The power circuit CCDTWB has the following components: deaerator (DA); deaerator pump (DAP); water-tube boiler (WB); extraction-condensing turbine (CDT); condenser (CD); and condenser pump (CDP). This circuit is selected because the watertube boiler is suited for the required steam pressure ("?pr " $\mathrm{kPa}>2,5 \mathrm{MPa}$ ) and also because extractioncondensing turbines can be used in both thermal and power-match mode.

)

Similar rules explain the selection of other circuits, as well as the plant operation mode.

\subsubsection{Object-oriented modeling}

Object-oriented modeling allows a proper representation of the entities related to a synthesis problem. Knowledge representation through classes of objects that relates to each other is known as ontology. The ontology defined for the

\begin{tabular}{|l|}
\hline \multicolumn{1}{|c|}{ POINT } \\
\hline plant: INTEGER \\
outlet: SYMBOL \\
inlet: SYMBOL \\
flow: FLOAT \\
pressure: FLOAT \\
temperature: FLOAT \\
espc-vol: FLOAT \\
enthalpy: FLOAT \\
entropy: FLOAT \\
quality: FLOAT \\
\hline calculate-ThermState (p1 vp1 p2 vp2) \\
\hline
\end{tabular}

Fig. 8 Attributes and procedures of point-class

domain considered in the present work is shown in Fig. 7. Note that defining a specific ontology is a modeling task, so it is possible to define different ontologies for the same problem. Depending on the degree of details, the entities may require several attributes and procedures, defining 
qualitative, quantitative and graphical features for each one. As an example, Fig. 8 shows the attributes and procedures of the point-class.

The system handles different real entities (e.g., the plant design and its circuits), so that the ontology depicted in Fig. 7 contains an embedded framework. This framework establishes a semantic network that connects all these different entities in a coherent manner. Power-class and process-class are subclasses of demand-class. Plant-class meets demand-class and is composed of circuit-class. Explanation-class embeds the design rationale and the point-class defines the thermodynamic state of all points of the plant-class. Design rationale means statements of reasoning underlying the design process that explain, derive, and justify design decisions [18]. It includes not only the reasons behind a design decision but also the justification for it, the other alternatives considered, the tradeoffs evaluated, and the argumentation that led to the decision [19].

\subsubsection{Thermodynamic state calculation}

$P-\nu-T$ equations are used to calculate the water thermodynamic state in both superheated and subcooled regions. For saturation region, IAPSW equations [20] are considered. The IAPSW equations for regions other than saturation are highly complex and quite hard to be approached in a computer environment that does not allow matrix and vector representation. For superheated and subcooled regions, the $P-v-T$ equations are Redlich-Kwong (1) and Tait $(2.1,2.2)$, respectively:

$$
\begin{aligned}
& P=\frac{0.4615 T}{v-0.001173}-\frac{43.951}{v(v+0.001173) T^{1 / 2}} \\
& v=0.001-3.15 \times 10^{-4} \log \left(\frac{B+P}{B+100}\right)
\end{aligned}
$$

$B=2.996 \times 10^{5}+755.54 \theta-17.814 \theta^{2}+6.08 \times 10^{-2} \theta^{3}$

where $\theta=T-298.15$.

It is also required the specific heat in both superheated (3) and subcooled (4) regions.

$$
\begin{aligned}
c_{p}= & 1.79+0.107 \times 10^{-3} T+0.586 \times 10^{-6} T \\
& -0.2 \times 10^{-9} T^{3} \\
c_{p}= & 5111-93.43 T+0.711 T^{2}-2.88 \times 10^{-3} T^{3}
\end{aligned}
$$

Enthalpy and entropy are then calculated through (5) and (6), respectively.

$$
h-h_{0}=\int_{T_{0}}^{T} c_{p} \mathrm{~d} T+\int_{P_{0}}^{P}\left(v-\left.T \frac{\partial v}{\partial T}\right|_{P}\right) \mathrm{d} P
$$

$s-s_{0}=\int_{T_{0}}^{T} c_{p} \frac{\mathrm{d} T}{T}-\left.\int_{P_{0}}^{P} \frac{\partial v}{\partial T}\right|_{P} \mathrm{~d} P$

Subscript 0 refers to an arbitrary reference state chosen as $T_{0}=273.15 \mathrm{~K} ; P_{0}=0.6108 \mathrm{kPa} ; h_{0}=0 \mathrm{~kJ} / \mathrm{kg} ; s_{0}=0 \mathrm{~kJ} /$ $\mathrm{kgK}$. Note that the procedure previously described allows the direct calculation of enthalpy and entropy (and also specific volume for subcooled liquid) from temperature and pressure. In order to determine, say, the temperature from pressure and enthalpy, Eq. (5) is solved iteratively.

\subsection{Computational implementation}

A rule is a structure composed of a set of premises and a set of consequences. The value of the set of premises is tested: if it is true, the set of consequences infer a new set of premises. The new set can be part of a new rule that can infer another set of premises and so on, creating an inference chain. In general, such inferences are too complex to be developed through classical logic, so that non-monotonic logics are required. Non-monotonic logics keep the set of premises true until a contradictory premise appears. The contradiction is eliminated by invalidating one of the premises related to the contradiction, which requires a truth maintenance strategy. Therefore, the KBS inference engine must be able to manipulate non-monotonic logic with a robust truth maintenance strategy. In order to avoid such a laborious and highly technical programming, a tool for KBS implementation should be used, which allows to concentrate effort on the knowledge base development.

There are several tools-known as shells-available for developing expert systems. The choice of a shell must take into account the inference chain and the form that the knowledge is represented. Design is a synthesis task related to a forward chaining reasoning, i.e., from facts it is reached a conclusion or solution. As seen in previous section, the knowledge is represented by rules, object-oriented modeling and semantic network. CLIPS [21] is a forward chaining shell based on pattern-matching architecture, where the knowledge can be represented in the form of rules, functions and object-oriented programming. CLIPS was originally developed by the NASA's Software Engineering Division. Nowadays it is public domain software that is maintained independently. Particularly, CLIPS allows the implementation of rules, object-oriented modeling and procedural functions, which is crucial to obtain a manageable and expandable knowledge representation scheme previously mentioned. On the other hand, CLIPS does not support matrix and vectors representation, which prevented the use of the more complex and accurate equations from IAPSW.

KBS prototype functional structure is presented in Fig. 9. User communicates with the prototype through a graphical interface developed in Java. The input data are 


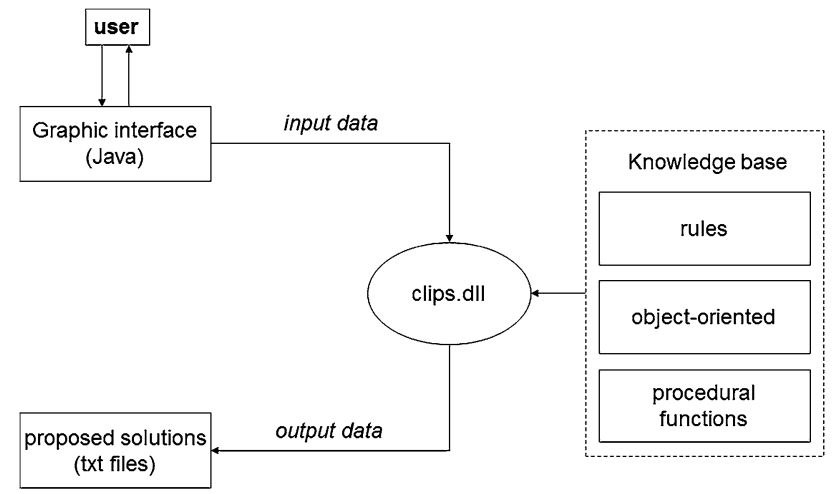

Fig. 9 KBS prototype functional structure

Table 2 Case study design requirements

\begin{tabular}{ll}
\hline Requirement & Value \\
\hline Steam at turbine inlet & \\
Pressure $(\mathrm{KPa})$ & 6000 \\
Temperature $(\mathrm{K})$ & 750 \\
Power & \\
Demand $(\mathrm{kW})$ & 1000 \\
Average daily consumption $(\mathrm{kWh})$ & 20,000 \\
Number of thermal processes & 3 \\
Process \#1 & \\
Pressure $(\mathrm{KPa})$ & 2000 \\
Flow $(\mathrm{kg} / \mathrm{s})$ & 4 \\
Water consumed $(\%)$ & 50 \\
Steam condition & Saturated \\
Process \#2 & \\
Pressure $(\mathrm{KPa})$ & 1500 \\
Flow $(\mathrm{kg} / \mathrm{s})$ & 3 \\
Water consumed $(\%)$ & 0 \\
Steam condition & Superheated \\
Process \#3 & \\
Pressure $(\mathrm{KPa})$ & 1000 \\
Flow $(\mathrm{kg} / \mathrm{s})$ & 2 \\
Water consumed $(\%)$ & 20 \\
Steam condition & Simirated \\
Access for cooling water & \\
\hline & \\
&
\end{tabular}

design requirements supplied by user. The data are processed by a dynamic-link library that contains the inference engine. Once the solutions are created, the inference engine exports them to a txt file.

\section{Results}

Due to the very nature of the design activity, i.e., synthesizing design requirements into conceptual solutions, it is

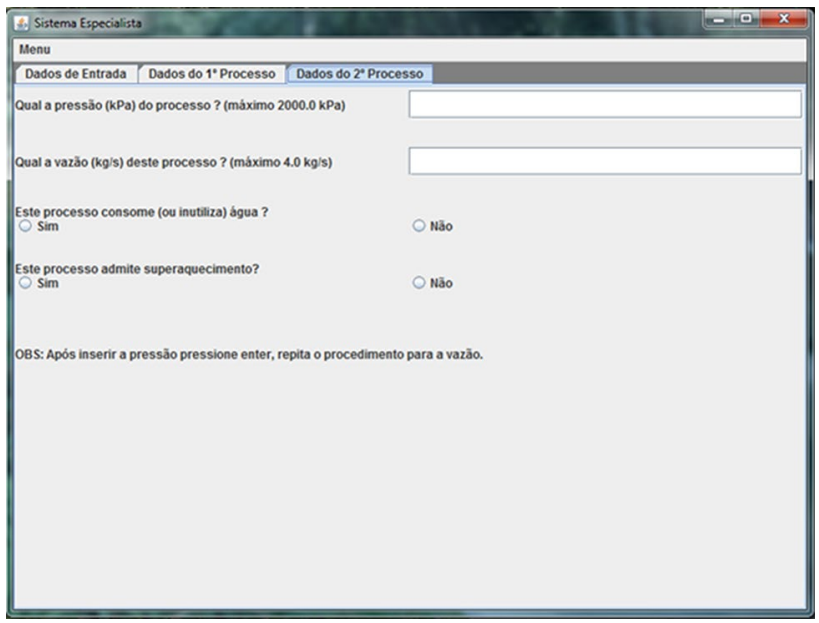

Fig. 10 Data input window

virtually impossible to show all the results that can be generated by the KBS prototype. Thus, a representative case study is executed by the KBS. Case study design requirements are presented in Table 2. Power and steam demands of a sugarcane industry should be met by a plant and the exceeding power can be commercialized.

Data input is made through the window shown in Fig. 10. After confirming all input data, KBS executes the inference chain and generates output files, one file per conceptual solution. In this case study, KBS generates three different conceptual solutions; the first one is presented in Table 3.

Output file is organized in three parts: (i) plant performance; (ii) thermodynamic state of each point; (iii) design rationale. The solution presented in Table 3 is described as follows. Biomass is burned in a water-tube boiler (WB) to provide high pressure, superheated steam. The steam is expanded in a BPT to generate power. Three extractions in the turbine casing provide steam for the respective processes. Since processes \#1 (PR1) and \#3 (PR3) demand saturated steam, desuperheaters (DS1 and DS3) are required upstream the respective processes. Part of the condensate generated by these processes is pumped back (DSP1 and DSP3, respectively) to the superheaters to transform superheated steam extracted from the turbine into saturated steam. Process \#2 (PR2) can use superheated steam, so that no desuperheated is required. Because process \#1 has the higher pressure, no pump is required to send the condensate of this process to the deaerator (DA). On the other hand, pumps (PRP2 and PR3) are required to send the condensate formed in processes \#2 and \#3 to the deaerator. The deaerator also receives make-up water to compensate the losses in processes \#1 and \#3. Thus, the condensate stored in the deaerator is a mixture of make-up water and condensate processes and is pumped back (DAP) to the boiler, 
Table 3 Conceptual solution \#1/3

\begin{tabular}{|c|c|c|c|c|c|c|c|c|}
\hline \multicolumn{9}{|c|}{$\begin{array}{l}\text { Plant 1: thermal-match operation } \\
\text { Application: sugar/cane industry }\end{array}$} \\
\hline \multicolumn{9}{|c|}{ Power generation performance parameters } \\
\hline \multicolumn{9}{|c|}{ Generated power: $2328.593 \mathrm{~kW}$} \\
\hline \multicolumn{9}{|c|}{ Net power: $2286.834 \mathrm{~kW}$} \\
\hline \multicolumn{9}{|c|}{ Exceeding power: $1286.834 \mathrm{~kW}$} \\
\hline \multicolumn{9}{|c|}{ Power required in the deaerator pump: $41.759 \mathrm{~kW}$} \\
\hline \multicolumn{9}{|c|}{ Power required in the process pump $2: 1.578 \mathrm{~kW}$} \\
\hline \multicolumn{9}{|c|}{ Power required in the process pump 3: $1.607 \mathrm{~kW}$} \\
\hline \multicolumn{9}{|c|}{ Thermal performance parameters } \\
\hline \multicolumn{9}{|c|}{ Heat required in the boiler: $22980.425 \mathrm{~kW}$} \\
\hline \multicolumn{9}{|c|}{ Heat required in the process $1: 7559.366 \mathrm{~kW}$} \\
\hline \multicolumn{9}{|c|}{ Heat required in the process $2: 6723.854 \mathrm{~kW}$} \\
\hline \multicolumn{9}{|c|}{ Heat required in the process $3: 4029.316 \mathrm{~kW}$} \\
\hline \multicolumn{9}{|c|}{ First law efficiency } \\
\hline \multicolumn{9}{|c|}{ Power: 0.0995} \\
\hline \multicolumn{9}{|c|}{ Thermal: 0.7969} \\
\hline \multicolumn{9}{|c|}{ Overall: 0.8964} \\
\hline \multicolumn{9}{|c|}{ Thermodynamic state } \\
\hline Point & Outlet & Inlet & $m(\mathrm{~kg} / \mathrm{s})$ & $P(\mathrm{kPa})$ & $T(\mathrm{~K})$ & $\begin{array}{l}h(\mathrm{~kJ} / \\
\mathrm{kg})\end{array}$ & $\begin{array}{l}s(\mathrm{~kJ} / \\
\mathrm{kgK})\end{array}$ & $X()$ \\
\hline 1 & DA & DAP & 8.408 & 2000.0 & 421.5 & 631.7 & 1.84 & Subcool \\
\hline 2 & DAP & WB & 8.408 & 6000.0 & 422.7 & 636.6 & 1.84 & Subcool \\
\hline 3 & WB & BPT & 8.408 & 6000.0 & 750.0 & 3369.9 & 6.829 & Superheat \\
\hline 4 & BPT & DS1 & 3.567 & 2000.0 & 619.0 & 3137.8 & 6.966 & Superheat \\
\hline 5 & DS1 & PR1 & 4.000 & 2000.0 & 485.5 & 2798.2 & 6.339 & 1.0 \\
\hline 6 & PR1 & DSP1 & 2.000 & 2000.0 & 485.5 & 908.4 & 2.446 & 0.0 \\
\hline 7 & DSP1 & DA & 1.567 & 2000.0 & 485.5 & 908.4 & 2.446 & 0.0 \\
\hline 8 & DSP1 & DS1 & 0.433 & 2000.0 & 485.5 & 908.4 & 2.446 & 0.0 \\
\hline 9 & BPT & PR2 & 3.000 & 1500.0 & 590.1 & 3085.7 & 7.007 & Superheat \\
\hline 10 & PR2 & PRP2 & 3.000 & 1500.0 & 471.4 & 844.5 & 2.314 & 0.0 \\
\hline 11 & PRP2 & DA & 3.000 & 2000.0 & 471.6 & 845.0 & 2.329 & Superheat \\
\hline 12 & BPT & DS3 & 1.840 & 1000.0 & 552.7 & 3017.8 & 7.068 & Superheat \\
\hline 13 & DS3 & PR3 & 2.000 & 1000.0 & 453.0 & 2777.1 & 6.585 & 1.0 \\
\hline 14 & PR3 & DSP3 & 1.600 & 1000.0 & 453.0 & 762.4 & 2.138 & 0.0 \\
\hline 15 & DSP3 & PRP3 & 1.440 & 1000.0 & 453.0 & 762.4 & 2.138 & 0.0 \\
\hline 16 & PRP3 & DA & 1.440 & 2000.0 & 453.3 & 763.6 & 2.145 & Subcool \\
\hline
\end{tabular}

closing the cycle. The diagram for this conceptual solution can be obtained from the inlet/outlet information presented in Table 3 and it is presented in Fig. 11.

The second conceptual solution is presented in Table 4. Biomass is burned in a water-tube boiler (WB), but steam is provided to an extraction-condensing turbine (CDT) to generate power. Like solution \#1, three extractions in turbine casing provide steam for the respective processes. Process steam streams from turbine extractions to deaerator are exactly the same for solutions \#1 and \#2. Additionally, the extraction-condensing turbine has an outlet for the condenser $(\mathrm{CD})$, so that the very low pressure condensate
Table 3 continued

\begin{tabular}{lllllllll}
\hline \multicolumn{2}{l}{ Thermodynamic state } \\
\hline Point & Outlet & Inlet & $m(\mathrm{~kg} / \mathrm{s})$ & $P(\mathrm{kPa})$ & $T(\mathrm{~K})$ & $\begin{array}{l}h(\mathrm{~kJ} / \\
\mathrm{kg})\end{array}$ & $\begin{array}{l}s(\mathrm{~kJ} / \\
\mathrm{kgK})\end{array}$ & $X()$ \\
\hline 17 & DSP3 & DS3 & 0.160 & 1000.0 & 453.0 & 762.4 & 2.138 & 0.0 \\
18 & env & DA & 2.400 & 2000.0 & 298.0 & 105.2 & 0.365 & Subcool \\
\hline
\end{tabular}

*** Design rationale: explanations for the plant 1 conceptual design

* Regarding the operation mode-Generally, plants operating in thermal-match mode are more efficient. However, the plant must be connected to the grid in order to either sell exceeding power or purchase power to complement the demand. In the present case, the plant can sell $1286.8 \mathrm{~kW}$ to the grid

* Regardin the plant configuration-Plant 1 is composed of 1 power generation circuit (CBPTWB) and 3 steam generation circuit(s) (CSCD1 CSGP2 CSGDP3). There is no need for a heat rejection circuit becuse the turbine is a back-pressure one

* Regarding the power generation circuit-The CBPTWB circuit is composed of deaerator (DA), deaerator pump (DAP), water-tube boiler (WB) and back-pressure turbine (BPT). The circuit is selected because the water-tube boiler is well suited for the required pressure $(6000 \mathrm{kPa}>2000 \mathrm{kPa})$. Furthermore, the back-pressure turbine is recommended for thermal-match mode

* Regarding the steam generation circuit(s) - The CSCD1 circuit is composed of desuperheater (DS1), the process 1 itself (PR1) and a small pump (DSP1) to feed the desuperheater. This is the process with the highest pressure and admits only saturated steam. Part of the condensate generated in the process is pumped back to the desuperheater in order to transform the superheated steam extracted from the turbine into saturated steam. No pump is required to send the condensate directly to the deaerator. Thus, the pressure of process 1 (2000 kPa) determines the deaerator operating pressure

The CSGP2 is composed of the process 2 itself (PR2) and a pump to return the condensate (PRP2). The circuit is selected because process 2 admits superheated steam from turbine extraction. The condensate is sent to the deaerator through a pump. Thus, the pump should raise the condensate pressure from process $2(1500 \mathrm{kPa})$ to the deaerator pressure $(2000 \mathrm{kPa})$

The CSGDP3 is composed of desuperheater (DS3), the process 3 itself (PR3), a small pump (DSP3) to feed the desuperheater and a pump to return the condensate (PRP3). The circuit is selected because process 3 admits saturated steam. Part of the condensate generated in the process is pumped back to the desuperheater in order to transform the superheated steam extracted from the turbine into saturated steam. The condensate is sent to the deaerator through a pump. Thus, the pump should raise the condensate pressure from process 3 (1000 $\mathrm{kPa})$ to the deaerator pressure $(2000 \mathrm{kPa})$

generated in this component is pumped (CDP) directly to the deaerator (DA). Like solution \#1, deaerator also receives make-up water. In this case, condensate stored in the deaerator is a mixture of make-up water and condensate from processes and condenser. The deaerator mixture is then pumped back (DAP) to the boiler, closing the cycle. The condenser is cooled by water coming from a dry cooling tower (DCT), which exchanges sensible heat with ambient air. The diagram of this solution is depicted in Fig. 12.

The only difference between the third conceptual solution (Table 5) and the second one is the condenser cooling, 
Fig. 11 Diagram of the conceptual solution \#1/3

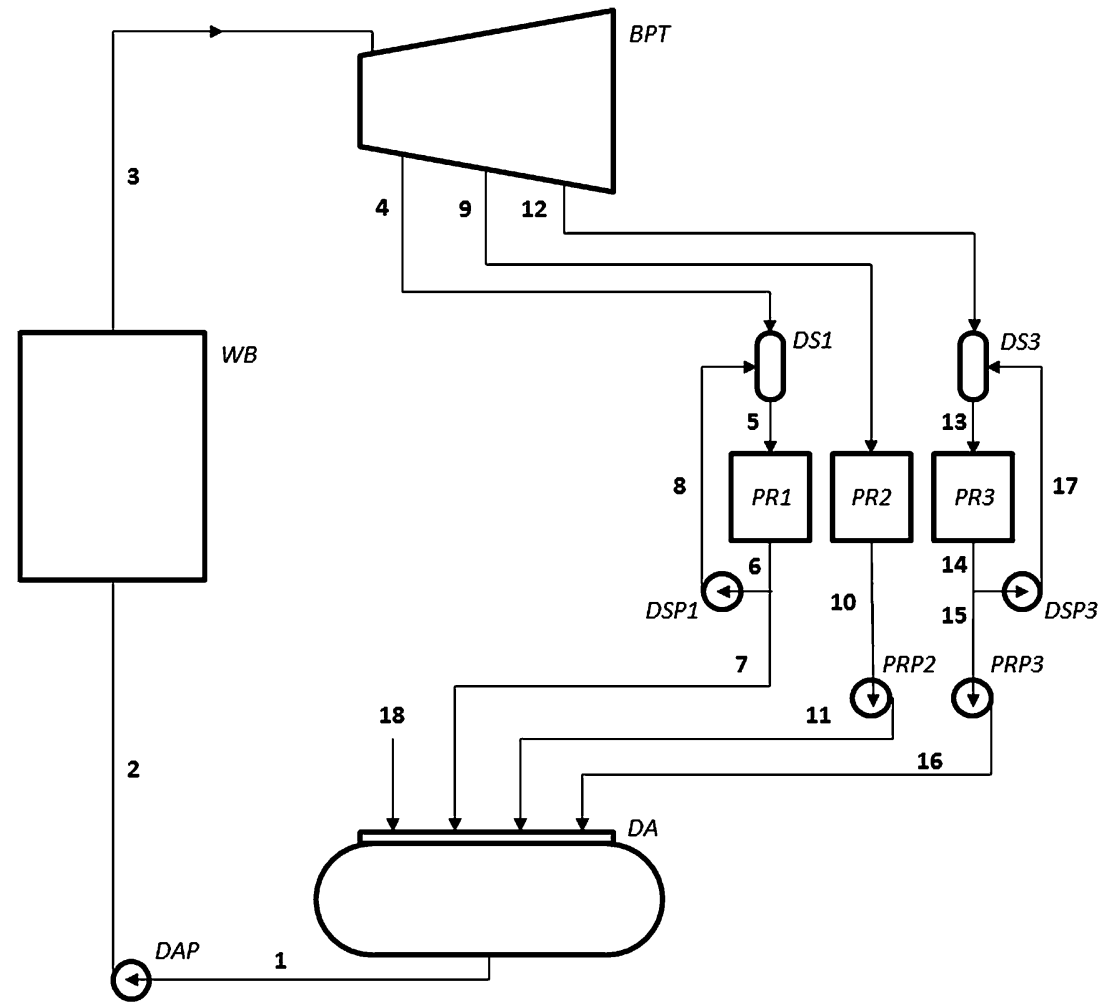

which is performed by water coming from a WCT, which exchanges sensible and latent heat with ambient air. The diagram of the third conceptual solution is presented in Fig. 13.

A comparison between solutions performance is presented in Table 6 . In solution \#1, all steam extracted from the turbine is used in the processes, a condenser is not required and heat rejection for the environment is avoided. Thus, this is the solution that presents the higher overall first Law efficiency. On the other hand, it presents the lowest power generation capacity and also the lowest power generation efficiency, which is expected due to the use of BPT. The overall efficiency of solutions \#2 and \#3 is lower than the solution \#1, but the power generation efficiency is greater. The exceeding power is also greater in these solutions, so that the revenue from the exceeding power commercialization may compensate the higher investment in an extraction-condensing turbine. As expected, the thermal-match operation results in exceeding power generation for commercialization for all solutions. As mentioned before, the only difference between the second and third conceptual is the condenser cooling. Due to some simplified hypothesis discussed in the next section, performance parameters of these solutions are equal.

\section{Discussion}

Some strong hypotheses are considered in KBS knowledge base. Boiler, turbine and pump efficiencies are considered constant and equal to $0.90,0.73$ and 0.85 , respectively. However, it is well known that larger components have higher efficiency $[13,16]$. Another simplification is considering condenser heat rejection independent on the cooling mode. For wet and dry towers, heat rejection is strongly dependent on the environmental conditions. Since wet towers mostly exchange latent heat, wet-bulb temperature plays a role as fundamental as dry-bulb temperature on the tower performance. On the other hand, dry towers exchange exclusively sensible heat, so that the dry-bulb temperature plays the major role on the performance. The reason for these simplifications is the focus on conceptual design, i.e., in determining one or more principles of solution able to meet design requirements. This is the design phase that demands more creativity and expertise from the engineer. By emulating that capacity, KBS is also able to create principles of solution. In its turn, performance parameters calculation is related to the preliminary design phase (see Sect. 2, items ii and iii). The KBS prototype can approach these calculations through conventional algorithmic functions, without the need to manipulate heuristic knowledge typically related to the conceptual design.

Regarding the figures related to the steam properties presented in Tables 3-5, it should be noted that there are errors up to $2 \%$ in the superheated and subcooled regions when compared to the IAPWS [20] formulation. The reason for that is the use of simpler $P-v-T$ equations to derive other properties, as shown in Sect. 2.2.3. This approach is considered 
Table 4 Conceptual solution \#2/3

Plant 2: thermal-match operation
Application: sugar/cane industry
Power generation performance parameters
Generated power: $4295.396 \mathrm{~kW}$
Net power: $4237.948 \mathrm{~kW}$
Exceeding power: $3237.948 \mathrm{~kW}$
Power required in the deaerator pump: $52.932 \mathrm{~kW}$
Power required in the condenser pump: $4.516 \mathrm{~kW}$
Power required in the process pump 2: $1.578 \mathrm{~kW}$
Power required in the process pump $3: 1.607 \mathrm{~kW}$
Thermal performance parameters
Heat required in the boiler: $3077.201 \mathrm{~kW}$
Heat rejected in the condenser: $5145.903 \mathrm{~kW}$
Heat required in the process $1: 7559.366 \mathrm{~kW}$
Heat required in the process $2: 6723.854 \mathrm{~kW}$
Heat required in the process $3: 4029.316 \mathrm{~kW}$
First law efficiency
Power: 0.1409
Thermal: 0.6089
Overall: 0.7498

\begin{tabular}{lllllllll}
\hline \multicolumn{1}{l}{ Thermodynamic state } & & & & & & \\
\hline Point & Outlet & Inlet & $m(\mathrm{~kg} / \mathrm{s})$ & $P(\mathrm{kPa})$ & $T(\mathrm{~K})$ & $h(\mathrm{~kJ} / \mathrm{kg})$ & $s(\mathrm{~kJ} /$ & $X()$ \\
& & & & & & & $\mathrm{kgK})$ & \\
\hline 1 & DA & DAP & 10.658 & 2000.0 & 421.5 & 631.7 & 1.84 & Subcool \\
2 & DAP & WB & 10.658 & 6000.0 & 422.7 & 636.6 & 1.84 & Subcool \\
3 & WB & CDT & 10.658 & 6000.0 & 750.0 & 3369.9 & 6.829 & Superheat \\
4 & CDT & CD & 2.250 & 12.3 & 323.0 & 2495.8 & 7.783 & 0.96 \\
5 & CD & CDP & 2.250 & 12.3 & 323.0 & 208.7 & 0.702 & 0.0 \\
6 & CDP & DA & 2.250 & 2000.0 & 323.5 & 210.7 & 0.702 & Subcool \\
7 & CDT & DS1 & 3.567 & 2000.0 & 619.0 & 3137.8 & 6.966 & Superheat \\
8 & DS1 & PR1 & 4.000 & 2000.0 & 485.5 & 2798.2 & 6.339 & 1.0 \\
9 & PR1 & DSP1 & 2.000 & 2000.0 & 485.5 & 908.4 & 2.446 & 0.0 \\
10 & DSP1 & DA & 1.567 & 2000.0 & 485.5 & 908.4 & 2.446 & 0.0 \\
11 & DSP1 & DS1 & 0.433 & 2000.0 & 485.5 & 908.4 & 2.446 & 0.0 \\
12 & CDT & PR2 & 3.000 & 1500.0 & 590.1 & 3085.7 & 7.007 & Superheat \\
13 & PR2 & PRP2 & 3.000 & 1500.0 & 471.4 & 844.5 & 2.314 & 0.0 \\
14 & PRP2 & DA & 3.000 & 2000.0 & 471.6 & 845.0 & 2.329 & Subcool \\
15 & CDT & DS3 & 1.840 & 1000.0 & 552.7 & 3017.8 & 7.068 & Superheat \\
16 & DS3 & PR3 & 2.000 & 1000.0 & 453.0 & 2777.1 & 6.585 & 1.0 \\
17 & PR3 & DSP3 & 1.600 & 1000.0 & 453.0 & 762.4 & 2.138 & 0.0 \\
18 & DSP3 & PRP3 & 1.440 & 1000.0 & 453.0 & 762.4 & 2.138 & 0.0 \\
19 & PRP3 & DA & 1.440 & 2000.0 & 453.3 & 763.6 & 2.145 & Subcool \\
20 & DSP3 & DS3 & 0.160 & 1000.0 & 453.0 & 762.4 & 2.138 & 0.0 \\
& & & & & & & &
\end{tabular}

because IAPWS equations for these regions have tens of terms and coefficients, which makes them very difficult to handle computationally in an environment that provides no vectors or matrix capabilities, such as CLIPS. On the other
Table 4 continued

\begin{tabular}{lllllllll}
\hline \multicolumn{7}{l}{ Thermodynamic state } \\
\hline Point & Outlet & Inlet & $m(\mathrm{~kg} / \mathrm{s})$ & $P(\mathrm{kPa})$ & $T(\mathrm{~K})$ & $h(\mathrm{~kJ} / \mathrm{kg})$ & $s(\mathrm{~kJ} /$ & $X()$ \\
& & & & & & $\mathrm{kgK})$ & \\
\hline 21 & env & DA & 2.400 & 2000.0 & 298.0 & 105.2 & 0.365 & Subcool \\
22 & DCT & CD & - & - & - & - & - & Subcool \\
23 & CD & DCT & - & - & - & - & - & Subcool \\
\hline
\end{tabular}

*** Design rationale: explanations for the plant 2 conceptual design

* Regarding the operation mode-Generally, plants operating in thermal-match mode are more efficient. However, the plant must be connected to the grid to either sell exceeding power or purchase power to complement the demand. In the present case, the plant can sell $1286.8 \mathrm{~kW}$ to the grid

* Regarding the plant configuration-Plant 2 is composed of 1 power generation circuit (CCDTWB), 3 steam generation circuit(s) (CSCD1 CSGP2 CSGDP3) and 1 heat rejection circuit (CHRDT)

* Regarding the power generation circuit-The CCDTWB circuit is composed of deaerator (DA), deaerator pump (DAP), water-tube boiler (WB), condensing turbine (CDT), condenser (CD) and condenser pump (CDP). The circuit is selected because the water-tube boiler is well suited for the required pressure $(6000 \mathrm{kPa}>2000 \mathrm{kPa})$. Furthermore, the condensing turbine is recommended for both powermatch and thermal-match modes

* Regarding the steam generation circuit(s) - The CSCD1 circuit is composed of desuperheater (DS1), the process 1 itself (PR1) and a small pump (DSP1) to feed the desuperheater. This is the process with the highest pressure and admits only saturated steam. Part of the condensate generated in the process is pumped back to the desuperheater to transform the superheated steam extracted from the turbine into saturated steam. No pump is required to send the condensate directly to the deaerator. Thus, the pressure of process $1(2000 \mathrm{kPa})$ determines the deaerator operating pressure

The CSGP2 is composed of the process 2 itself (PR2) and a pump to return the condensate (PRP2). The circuit is selected because process 2 admits superheated steam from turbine extraction. The condensate is sent to the deaerator through a pump. Thus, the pump should raise the condensate pressure from process $2(1500 \mathrm{kPa})$ to the deaerator pressure $(2000 \mathrm{kPa})$

The CSGDP3 is composed of desuperheater (DS3), the process 3 itself (PR3), a small pump (DSP3) to feed the desuperheater and a pump to return the condensate (PRP3). The circuit is selected because process 3 admits saturated steam. Part of the condensate generated in the process is pumped back to the desuperheater in order to transform the superheated steam extracted from the turbine into saturated steam. The condensate is sent to the deaerator through a pump. Thus, the pump should raise the condensate pressure from process 3

$(1000 \mathrm{kPa})$ to the deaerator pressure $(2000 \mathrm{kPa})$

* Regarding the heat rejection circuit-The CHRDT circuit is composed of a pump that moves water from a dry cooling tower to the condenser. After the heat exchanging in the condenser, the water returns to the tower to be cooled exclusively through sensible heat exchanging. This is the less efficient mode for condenser cooling and may require quite high towers to allow a proper natural circulation of air. Its performance is strongly dependent on the environmental conditions, especially the dry-bulb temperature. On the other hand, dry towers do not require mechanical driving for air moving; also, there is virtually no water loss, which makes them well suited for low availability of water 
Fig. 12 Diagram of the conceptual solution \#2/3

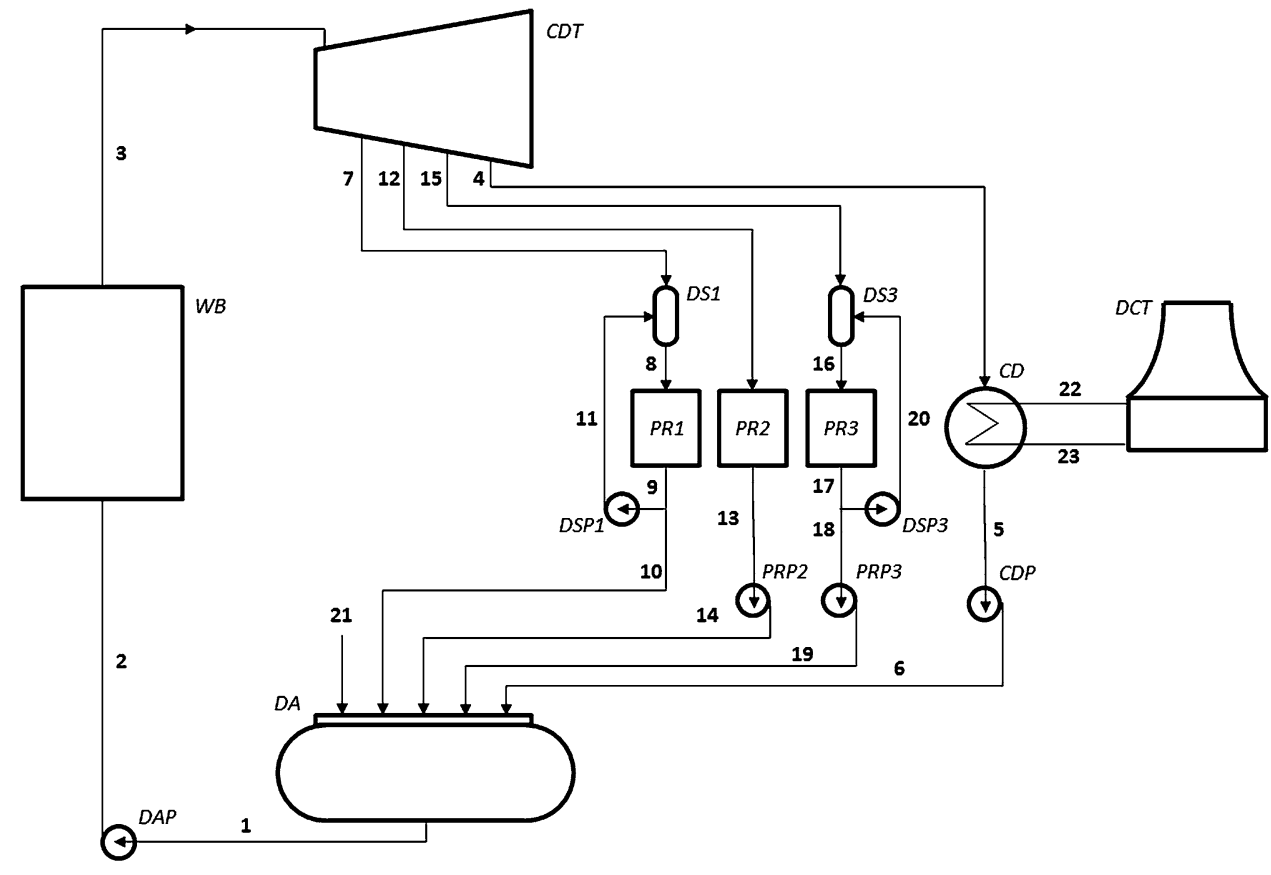

hand, the IAPWS equations for the saturated regions are simpler and their implementation in CLIPS is easily made.

Since the KBS is a supporting tool that provides workable principles of solution, the final decision is up to the designer and depends mainly on economic and environmental restrictions. For example, using water from a river for condenser cooling is probably the most cost-effective alternative, but it also presents several environmental barriers to be accepted. The efficiency is the most important parameter of performance, but it does not mean that other parameters can be disregarded. For instance, conceptual solution \#1 presents the highest efficiency, but it also presents the lowest exceeding power. Therefore, the lower revenue from the commercialization of the exceeding power may contribute to reduce the economic attractiveness of this solution. On the other hand, conceptual solution \#2 is less efficient, but it may present higher income from selling the exceeding power. However, from an environmental point-of-view, especially those related to pollutant emissions, the most efficient concept is desirable. In scenarios in which emissions are taxed, plants that are more efficient can become more attractive.

As can be noted from this discussion, there are many objectives and restrictions that difficult the designer to make a decision, so that optimization techniques should be considered. There are several works in the literature dealing with this subject in the field of thermal/energy systems [4, 22-24]. The main role of the KBS proposed here is to provide high quality conceptual solutions that have sufficient merit to be optimized, a requirement pointed out by Bejan et al. [4]. The refinement of the conceptual solution is performed during the preliminary design step of the methodology proposed by Pahl et al. [3] and it is out of the scope of the present work.

Finally, it must be emphasized that the KBS presented here is a rapid prototype, i.e., a working version of the system that allows to identify any gaps, inconsistencies or errors in the implemented knowledge base, so that (i) corrections can be made immediately, and (ii) new knowledge can be incrementally added to the knowledge base [17]. Thus, the development of any KBS is an endless working in progress, since an "expert system can never really be finished-it only keeps getting better" [17]. Such a constant knowledge base expansion requires a knowledge representation scheme flexible enough, as the combination of rules, object-oriented and semantic network described in Sect. 2.

\section{Conclusion}

In the present work, it was demonstrated the development of a KBS for conceptual design of biomass cogeneration plants. Elicitation from experts and technical literature provided the knowledge for the base. The knowledge representation scheme was detailed focusing on its flexibility to cope with future knowledge base expansion. The use of a shell to implement the knowledge base proved to be crucial for rapid prototyping. On the other hand, some shell limitations prevented a highly accurate calculation of steam properties for superheated and subcooled regions, so that $P-v-T$ equations were considered. Despite the assumption of some oversimplified hypothesis, the system was able to quickly 
Table 5 Conceptual solution \#3/3

\section{Plant 3: thermal-match operation \\ Application: sugar/cane industry \\ Power generation performance parameters \\ Generated power: $4295.396 \mathrm{~kW}$ \\ Net power: $4237.948 \mathrm{~kW}$ \\ Exceeding power: $3237.948 \mathrm{~kW}$ \\ Power required in the deaerator pump: $52.932 \mathrm{~kW}$ \\ Power required in the condenser pump: $4.516 \mathrm{~kW}$ \\ Power required in the process pump 2: $1.578 \mathrm{~kW}$ \\ Power required in the process pump 3: $1.607 \mathrm{~kW}$ \\ Thermal performance parameters \\ Heat required in the boiler: $3077.201 \mathrm{~kW}$ \\ Heat rejected in the condenser: $5145.903 \mathrm{~kW}$ \\ Heat required in the process $1: 7559.366 \mathrm{~kW}$ \\ Heat required in the process 2: $6723.854 \mathrm{~kW}$ \\ Heat required in the process 3: $4029.316 \mathrm{~kW}$ \\ First law efficiency \\ Power: 0.1409 \\ Thermal: 0.6089 \\ Overall: 0.7498}

Thermodynamic state

\begin{tabular}{|c|c|c|c|c|c|c|c|c|}
\hline Point & Outlet & Inlet & $m(\mathrm{~kg} / \mathrm{s})$ & $P(\mathrm{kPa})$ & $T(\mathrm{~K})$ & $h(\mathrm{~kJ} / \mathrm{kg})$ & $\begin{array}{l}s(\mathrm{~kJ} / \\
\mathrm{kgK})\end{array}$ & $X()$ \\
\hline 1 & DA & DAP & 10.658 & 2000.0 & 421.5 & 631.7 & 1.84 & Subcool \\
\hline 2 & DAP & WB & 10.658 & 6000.0 & 422.7 & 636.6 & 1.84 & Subcool \\
\hline 3 & WB & CDT & 10.658 & 6000.0 & 750.0 & 3369.9 & 6.829 & Superhea \\
\hline 4 & CDT & $\mathrm{CD}$ & 2.250 & 12.3 & 323.0 & 2495.8 & 7.783 & 0.96 \\
\hline 5 & $\mathrm{CD}$ & $\mathrm{CDP}$ & 2.250 & 12.3 & 323.0 & 208.7 & 0.702 & 0.0 \\
\hline 6 & $\mathrm{CDP}$ & DA & 2.250 & 2000.0 & 323.5 & 210.7 & 0.702 & Subcool \\
\hline 7 & CDT & DS1 & 3.567 & 2000.0 & 619.0 & 3137.8 & 6.966 & Superh \\
\hline 8 & DS1 & PR1 & 4.000 & 2000.0 & 485.5 & 2798.2 & 6.339 & 1.0 \\
\hline 9 & PR1 & DSP1 & 2.000 & 2000.0 & 485.5 & 908.4 & 2.446 & 0.0 \\
\hline 10 & DSP1 & DA & 1.567 & 2000.0 & 485.5 & 908.4 & 2.446 & 0.0 \\
\hline 11 & DSP1 & DS1 & 0.43 & 2000.0 & 485.5 & 908.4 & 2.446 & 0.0 \\
\hline 12 & CDT & PR2 & 3.000 & 1500.0 & 590.1 & 3085.7 & 7.007 & Superhea \\
\hline 13 & PR2 & PRP2 & 3.000 & 1500.0 & 471.4 & 844.5 & 2.314 & 0.0 \\
\hline 14 & PRP2 & DA & 3.000 & 2000.0 & 471.6 & 845.0 & 2.329 & Subcool \\
\hline 15 & CDT & DS3 & 1.840 & 1000.0 & 552.7 & 3017.8 & 7.068 & Superher \\
\hline 16 & DS3 & PR3 & 2.000 & 1000.0 & 453.0 & 2777.1 & 6.585 & 1.0 \\
\hline 17 & PR3 & DSP3 & 1.600 & 1000.0 & 453.0 & 762.4 & 2.138 & 0.0 \\
\hline 18 & DSP3 & PRP3 & 1.440 & 1000.0 & 453.0 & 762.4 & 2.138 & 0.0 \\
\hline 19 & PRP3 & DA & 1.440 & 2000.0 & 453.3 & 763.6 & 2.145 & Subcool \\
\hline 20 & DSP3 & DS3 & 0.160 & 1000.0 & 453.0 & 762.4 & 2.138 & 0.0 \\
\hline
\end{tabular}

provide high quality conceptual solutions to support the designer in his/her decision making. Since the knowledge representation scheme is flexible enough to cope with new
Table 5 continued

\begin{tabular}{lllllllll}
\hline \multicolumn{2}{l}{ Thermodynamic state } \\
\hline Point & Outlet & Inlet & $m(\mathrm{~kg} / \mathrm{s})$ & $P(\mathrm{kPa})$ & $T(\mathrm{~K})$ & $h(\mathrm{~kJ} / \mathrm{kg})$ & $\begin{array}{l}s(\mathrm{~kJ} / \\
\mathrm{kgK})\end{array}$ & $X()$ \\
\hline 21 & env & DA & 2.400 & 2000.0 & 298.0 & 105.2 & 0.365 & Subcool \\
22 & DCT & CD & - & - & - & - & - & Subcool \\
23 & CD & DCT & - & - & - & - & - & Subcool \\
\hline
\end{tabular}

*** Design rationale: explanations for the plant 3 conceptual design

* Regarding the operation mode-Generally, plants operating in thermal-match mode are more efficient. However, the plant must be connected to the grid to either sell exceeding power or purchase power to complement the demand. In the present case, the plant can sell $1286.8 \mathrm{~kW}$ to the grid

* Regarding the plant configuration-Plant 2 is composed of 1 power generation circuit (CCDTWB), 3 steam generation circuit(s) (CSCD1 CSGP2 CSGDP3) and 1 heat rejection circuit (CHRWT)

* Regarding the power generation circuit-The CCDTWB circuit is composed of deaerator (DA), deaerator pump (DAP), water-tube boiler (WB), condensing turbine (CDT), condenser (CD) and condenser pump (CDP). The circuit is selected because the water-tube boiler is well suited for the required pressure $(6000 \mathrm{kPa}>2000 \mathrm{kPa})$ Furthermore, the condensing turbine is recommended for both powermatch and thermal-match modes

* Regarding the steam generation circuit(s) - The CSCD1 circuit is composed of desuperheater (DS1), the process 1 itself (PR1) and a small pump (DSP1) to feed the desuperheater. This is the process with the highest pressure and admits only saturated steam. Part of the condensate generated in the process is pumped back to the desuperheater to transform the superheated steam extracted from the turbine into saturated steam. No pump is required to send the condensate directly to the deaerator. Thus, the pressure of process $1(2000 \mathrm{kPa})$ determines the deaerator operating pressure

The CSGP2 is composed of the process 2 itself (PR2) and a pump to return the condensate (PRP2). The circuit is selected because process 2 admits superheated steam from turbine extraction. The condensate is sent to the deaerator through a pump. Thus, the pump should raise the condensate pressure from process $2(1500 \mathrm{kPa})$ to the deaerator pressure $(2000 \mathrm{kPa})$

The CSGDP3 is composed of desuperheater (DS3), the process 3 itself (PR3), a small pump (DSP3) to feed the desuperheater and a pump to return the condensate (PRP3). The circuit is selected because process 3 admits saturated steam. Part of the condensate generated in the process is pumped back to the desuperheater to transform the superheated steam extracted from the turbine into saturated steam. The condensate is sent to the deaerator through a pump. Thus, the pump should raise the condensate pressure from process 3

$(1000 \mathrm{kPa})$ to the deaerator pressure $(2000 \mathrm{kPa})$

* Regarding the heat rejection circuit-The CHRWT circuit is composed of a pump that moves water from a wet cooling tower to the condenser. After the heat exchanging in the condenser, the water returns to the tower to be cooled through both sensible and latent heat exchanging. This is a reasonably efficient mode for condenser cooling, but its performance is strongly dependent on the environmental conditions, especially the dry and wet-bulb temperatures. On the other hand, wet towers do require mechanical driving for air moving; also, the evaporated water in the latent heat exchanging must be refilled, which demands some availability of water 
Fig. 13 Diagram of the conceptual solution \#3/3

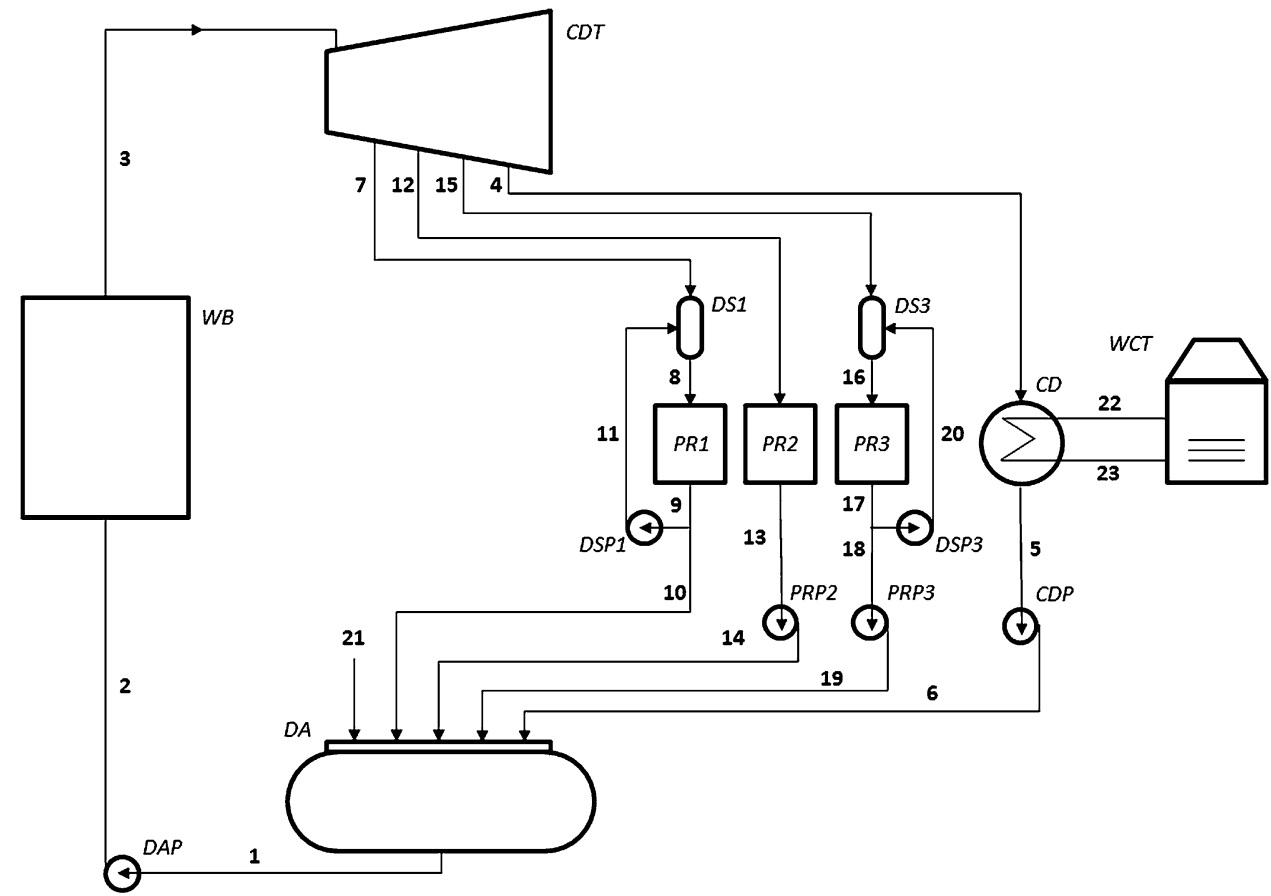

Table 6 Comparison between solutions

\begin{tabular}{lll}
\hline Performance parameters & Solution \#1 & Solutions \#2 and \#3 \\
\hline Power (kW) & & \\
Generated power & 2328.593 & 4295.396 \\
Net power & 2286.834 & 4237.948 \\
Exceeding power & $1286.834 \mathrm{~kW}$ & 3237.948 \\
Power required in the deaerator pump & 41.759 & 52.932 \\
Power required in the condenser pump & - & 4.516 \\
Power required in the process pump 2 & 1.578 & 1.578 \\
Power required in the process pump 3 & 1.607 & 1.607 \\
Thermal (kW) & & \\
Heat required in the boiler & 22980.425 & 3077.201 \\
Heat rejected in the condenser & - & 5145.903 \\
Heat required in the process 1 & 7559.366 & 7559.366 \\
Heat required in the process 2 & 6723.854 & 6723.854 \\
Heat required in the process 3 & 4029.316 & 4029.316 \\
First law efficiency & & \\
Power & 0.0995 & 0.1409 \\
Thermal & 0.7969 & 0.6089 \\
Overall & 0.8964 & 0.7498 \\
\hline
\end{tabular}

knowledge, it is expected that the rapid prototype presented here keeps evolving towards a more robust and reliable expert system.

Acknowledgments The author gratefully acknowledges: (i) the contributions of the experts and fellows Prof. J. A. P. Balestieri and
Prof. R. A. Dias, for sharing their expertise in cogeneration and power generation; (ii) the contributions of the undergraduate students Fernando Luz dos Santos e Bruno Robson Pinto, for helping with the knowledge base and interface; (iii) the support from the São Paulo Research Foundation (FAPESP) under Grants 2011/19099-1, 2012/12567-2 and 2013/06907-8. 


\section{References}

1. Shena Y, Yoshikawaa K (2013) Recent progresses in catalytic tar elimination during biomass gasification or pyrolysis-a review. Renew Sustain Energy Rev 21:371-392

2. Choudhury A, Chandra H, Arora A (2013) Application of solid oxide fuel cell technology for power generation-a review. Renew Sustain Energy Rev 20:430-442

3. Pahl G, Beitz W, Feldhusen J, Grote KH (2007) Engineering design: a systematic approach. Springer, Berlin

4. Bejan A, Tsatsaronis G, Moran M (1996) Thermal design and optimization. Wiley, New York

5. Silva JC, Back N (2000) Shaping the process of fluid power system design applying an expert system. Res Eng Des 12:08-17

6. Mandow L, Pérez-de-la-Cruz J (2004) Sindi: an intelligent assistant for highway design. Expert Syst Appl 27:635-644

7. Hernandez C, Arjona MA (2008) An intelligent assistant for designing distribution transforms. Expert Syst Appl 34:1931-1937

8. Melli R, Paoletti B, Sciubba E (1992) SYSLAM: an interactive expert system approach to power plant design and optimization. Int J Energy Environ Econ 2:165-175

9. Melli R, Sciubba E (1997) A prototype expert system for the conceptual synthesis of thermal processes. Energy Conv Manag 38:1737-1749

10. Manolas DA, Efthimeros GA, Tsahalis DT (2001) Development of an expert system shell based on genetic algorithms for the selection of the energy best available technologies and their optimal operating conditions for the process industry. Expert Syst 18:124-130

11. Matelli JA, Silva JC, Bazzo E (2009) An expert system prototype for designing natural gas cogeneration plants. Expert Syst Appl $36: 8375-8384$
12. Silva JC, Saxenab A, Balabana E, Goebela K (2012) A knowledge-based system approach for sensor fault modeling, detection and mitigation. Expert Syst Appl 39:10977-10989

13. Bazzo E (1995) Steam generation. Ed. da UFSC, Florianópolis (in Portuguese)

14. Orlando JA (1996) Cogeneration design guide. ASHRAE, Atlanta

15. Balestieri JAP (2002) Cogeneration: combined generation of heat and power. Ed. da UFSC, Florianópolis (in Portuguese)

16. Borgnakke C, Sonntag RE (2008) Fundamentals of thermodynamics. Wiley, New York

17. Giarratano J, Riley G (1998) Expert systems: principles and programming. PWS Publishing Company, Boston

18. Fischer G, Lemke A, McCall R, Morch A (1995) Making argumentation serve design. In: Moran T, Carroll J (eds) Design rationale: concepts, techniques, and use. Lawrence Erlbaum Associates, London, pp 267-294

19. Lee J (1997) Design rationale systems: understanding the issues. IEEE Expert 12:78-85

20. Wagner W, Pruß A (2002) The IAPWS formulation 1995 for the thermodynamic properties of ordinary water substance for general and scientific use. J Phys Chem Ref Data 31:387-535

21. CLIPS (2014) C-language integrated production system, version 6.30 beta. http://clipsrules.sourceforge.net/. Accessed 12 March 2014

22. Stoecker WF (1989) Design of thermal systems. McGraw-Hill, New York

23. Balestieri JAP, Correa PB (1997) Multiobjective linear model for pre-feasibility designs of cogeneration systems. Energy 39:537-548

24. Ferreira EM, Balestieri JAP, Zanardi MA (2010) Optimization analysis of dual-purpose systems. Desalination 250:936-944 